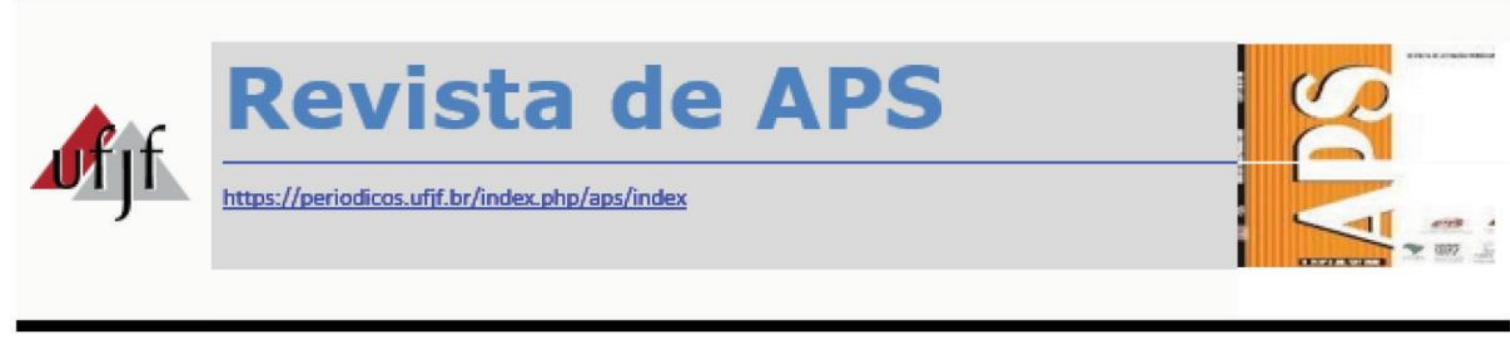

\title{
Qualidade da atenção em Saúde Bucal: entraves que dificultam a prática das Equipes de Saúde Bucal na Estratégia de Saúde da Família
}

\author{
Quality of care in oral health: obstacles that hinder the practice of Oral \\ Health Teams in the Family Health Strategy
}

\begin{abstract}
Ana Áurea Alécio de Oliveira Rodrigues ${ }^{1}$, Manuela Queiroz Oliveira ${ }^{2}$, Marcos Heitor Assis dos Santos ${ }^{3}$, Agenor de Jesus Júnior ${ }^{4}$, Alana Késia Pastor da Silva ${ }^{5}$
\end{abstract}

\begin{abstract}
RESUMO
Após 16 anos de implantação das Equipes de Saúde Bucal (ESB), no Brasil, muitas cidades ainda não lograram a produção do cuidado em saúde conforme o preconizado pelo SUS. Diante disto, este estudo tem como objetivo compreender e discutir os fatores que dificultam as práticas das ESB na Estratégia de Saúde da Família por meio de uma abordagem qualitativa. Para a realização deste trabalho, utilizou-se como instrumento de coleta dos dados entrevista semiestruturada, aplicada a 29 indivíduos, participantes de Equipes de Saúde Bucal e outros profissionais da saúde, gestores e usuários de seis unidades de saúde de um município do Território do Sisal. A análise foi baseada na hermenêutica-dialética. A insuficiente cobertura em saúde bucal, a alta demanda, a forma de organização do serviço, a precariedade do vínculo empregatício e o baixo financiamento em saúde foram os entraves encontrados no município, que influenciam negativamente no processo do cuidado em saúde e não favorecem a oferta de um serviço de qualidade que proporcione a resolubilidade da atenção.

Palavras-chave: Saúde bucal. Estratégia de Saúde da Família. Prática de saúde pública.

\footnotetext{
1 Professora Assistente do curso de Odontologia, Especialista em Saúde da Família, Mestre em Saúde Coletiva, pesquisadora do Núcleo de Pesquisa Integrada em Saúde Coletiva (NUPISC) da Universidade Estadual de Feira de Santana (UEFS). E-mail: aleccio@terra.com.br

2 Cirurgiã-dentista graduada pela Universidade Estadual de Feira de Santana.

${ }^{3}$ Cirurgião-dentista graduada pela Universidade Estadual de Feira de Santana.

${ }^{4}$ Discente na Universidade Estadual de Feira de Santana.

${ }^{5}$ Discente na Universidade Estadual de Feira de Santana.
} 


\begin{abstract}
After 16 years of implementation of the Oral Health Teams (OHT), in Brazil, many cities have not yet achieved the production of health care as recommended by the SUS. In view of this, this study aims to understand and discuss the factors that hinder the ESB practices in the Family Health Strategy through a qualitative approach. For this study, a semi structured interview was used as an instrument for data collection, applied to 29 individuals, participants of Oral Health Teams and other health professionals, managers and users of six health units of a municipality of the Sisal territory. The analysis was based on the hermeneutics-dialectics technique. The insufficient coverage of oral health, the high demand, the form of organization of service, the precariousness of the employment and low funding in health were the obstacles encountered in the city, and they influence negatively in the health care process and do not favor the provision of a quality service that provides the resoluteness of care.
\end{abstract}

KEYWORDS: Oral health. Family Health Strategy. Public Health Practice.

\title{
INTRODUÇÃO
}

A Estratégia Saúde da Família (ESF) surgiu em 1994 como recurso para fortalecer a construção e consolidação do Sistema Único de Saúde (SUS), possui a família como núcleo central do cuidado e tem intenção de resolver grande parte das problemáticas de saúde na atenção básica ${ }^{1}$.

Em 2000, com objetivo de levar os princípios da ESF para a saúde bucal, o Ministério da Saúde, por meio da Portaria 1.444², inclui Equipes de Saúde Bucal (ESB) nas Unidades de Saúde da Família, cuja estrutura foi regulamentada pela Portaria no 267, de 6 de março de $2001^{3}$. Segundo Barbosa et al. ${ }^{4}$, essa iniciativa teve como propósito atendimento igualitário e humanizado, por meio do trabalho da ESB articulado com os demais membros da equipe. Entretanto, Pezzato et al. ${ }^{5}$ ressaltam que a produção do cuidado em saúde ocorre em espaço de disputa dos projetos que operam no interior das instituições e que a saúde bucal vem lutando para se consolidar no âmbito do SUS.

Segundo Pucca Jr. ${ }^{6: 243}$, para a organização deste modelo,

é fundamental que sejam pensadas as linhas do cuidado da criança, do adolescente, do adulto, do idoso, com a criação de fluxos que impliquem ações resolutivas das equipes de saúde, centradas no acolher, informar, atender e encaminhar. Acima de tudo em que o usuário, através de um acesso que não lhe deve ser negado, conheça cada lugar que compõe a estrutura do serviço a partir da sua vivência nele. A linha do cuidado implica um redirecionamento do processo de trabalho, no qual o bom funcionamento da equipe de trabalho é um de seus fundamentos mais importantes.

Para Mattos et al. ${ }^{7}$, os principais motivos para incorporação das ESB nas Equipes de Saúde da Família (EqSF) pelos municípios são o incentivo financeiro oferecido pelo 
Ministério da Saúde e a crença dos gestores de que esse novo modelo pode melhorar a saúde bucal da população e a reorganizar as ações.

No entanto, estudos ${ }^{8-13}$ que analisam o processo de trabalho das ESB mostraram que sua implantação na ESF ainda não reflete o que propõe a portaria 267. Pesquisa realizada por Tavares et al. ${ }^{8}$, cujo objetivo foi conhecer a organização da oferta dos serviços em saúde bucal em um município da Bahia, identificou barreiras funcionais para acessibilidade aos mesmos, em razão da falta de materiais e da dificuldade para manutenção dos equipamentos. Além desses fatores, ressaltaram que não foi constatada a participação dos usuários na organização das ações em saúde.

Sobre os processos de participação popular no Saúde da Família, resultado de estudo realizado por Pimentel et al. ${ }^{14}$, no estado de Pernambuco, mostraram que apenas 24,0\% das ESB se reúnem com a comunidade periodicamente para debater temas sobre cidadania, assistência, funcionamento do SUS e em apenas 19,3\% existem a participação de representantes de movimentos sociais e usuários no processo de planejamento do trabalho da equipe.

Por sua vez, Rodrigues e Assis ${ }^{9}$, ao investigarem a dinâmica sobre a oferta e a demanda na atenção à saúde bucal na ESF de um município baiano, mostraram que o cirurgião-dentista (CD) muitas vezes apresenta uma relação impessoal e autonomizada com o usuário, devido à grande demanda e pouca oferta, secundarizando, assim, a tecnologia leve ${ }^{10}$, a produção de relações no momento dos encontros entre os sujeitos (profissionais, equipe e usuários), estabelecendo vínculo, acolhimento e confiança por meio da percepção da singularidade de cada indivíduo.

Quando o usuário consegue o atendimento clínico, de acordo com os resultados encontrados por Santos et al. ${ }^{11}$, o mesmo é realizado de maneira rápida e pontual, voltado para a queixa e restrito à quantidade de vagas e equipamentos disponíveis no momento da consulta. Porém, para garantir a resolubilidade do serviço, compreendida como a aplicação adequada das tecnologias em saúde para a produção do cuidado, faz-se necessário um olhar integral voltado para a totalidade do indivíduo que possui necessidades em saúde ${ }^{12}$.

Bomfim et al. ${ }^{13}$, corroborando com os achados acima, concluíram que o CD vê o paciente de forma fragmentada e não garante resolubilidade das ações por não ter foco na família e na comunidade. Observaram também que os gestores não possuem domínio sobre o processo de inclusão e funcionamento da Saúde Bucal dentro da EqSF.

Ao procurar entender os motivos para as principais limitações na operacionalização das ESB, Conill ${ }^{15}$ concluiu que são decorrentes da formação inadequada dos profissionais e gestores, deficiência de recursos financeiros e falta de entendimento das estratégias de execução dos serviços e das ações de saúde preconizadas pela política de saúde atual. 
Diante do exposto, é possível considerar que em muitas cidades a produção do cuidado em saúde bucal ainda não ocorre conforme o preconizado pelos princípios e diretrizes do SUS. O objetivo deste trabalho é compreender e discutir os fatores que dificultam as práticas das Equipes de Saúde Bucal na Estratégia de Saúde da Família em município do semiárido baiano.

\section{MATERIAL E MÉTODOS}

A contextualização das políticas em saúde deve ser compreendida a partir de conflitos que se estabelecem entre os sujeitos envolvidos no campo concreto da práxis social. Portanto, tornase necessário estabelecer interfaces que desvendem as nuances das práticas em saúde a partir de sua inserção num contexto social, econômico, político e ideológico, que é dinâmico e engendrado historicamente. ${ }^{16: 465}$

Para a realização deste trabalho, optamos por uma abordagem qualitativa que possibilita responder a questões sociais, com a compreensão dos seres humanos e da natureza, de suas relações intrassubjetivas e com a realidade social ${ }^{17}$. Para campo de estudo, selecionamos um município da Bahia, situado na região do Território do Sisal, área de intervenção do projeto "Levantamento das condições de Saúde Bucal e organização do trabalho das equipes de Saúde Bucal no território do Sisal" do Programa de Educação Tutorial do Curso de Odontologia da Universidade Estadual de Feira de Santana (PET-Odontologia/UEFS).

O projeto ao qual este trabalho se refere foi aprovado pelo Comitê de Ética em Pesquisa da UEFS sob protocolo no 097/2010, CAAE 0096.0.059.000-10, em 29/12/2010, cumprindo assim os preceitos éticos das pesquisas com seres humanos. Todos os participantes da pesquisa assinaram o Termo de Consentimento Livre e Esclarecido (TCLE).

O município estudado situa-se na Mesorregião do Nordeste Baiano, Microrregião Geográfica de Serrinha, no território de identidade do Sisal, estado da Bahia. Possui clima Tropical Semiárido e situa-se no bioma da Caatinga, com predominância de vegetação arbórea aberta, com palmeiras. Insere-se na região geoeconômica do sisal e se destaca na produção da fibra com título de liderança da região ${ }^{18}$.

Tomamos como cenário de estudo seis Unidades de Saúde da Família (USF) com ESB. A escolha dessas unidades e dos participantes do estudo foi intencional, levandose em consideração a facilidade do acesso. Das seis unidades de saúde selecionadas, quatro estão situadas na zona urbana e duas na zona rural. Os participantes da pesquisa foram divididos em quatro grupos (Quadro 1): 
Quadro 1 - Distribuição dos participantes da pesquisa por Grupos

\begin{tabular}{|l|l|l|}
\hline Grupo & \multicolumn{1}{|c|}{ Composição } & \multicolumn{1}{|c|}{ Justificativa } \\
\hline I & $\begin{array}{l}\text { Cirurgião-dentista (CD), auxiliar de saúde bucal } \\
\text { (ASB) e técnico de saúde bucal (TSB), que } \\
\text { atuam no Programa de Saúde da Família e no } \\
\text { Centro de Especialidades Odontológicas (CEO) } \\
\text { do município estudado. }\end{array}$ & $\begin{array}{l}\text { Representa os profissionais que } \\
\text { exercem a prática em saúde bucal } \\
\text { dentro da equipe da ESF. }\end{array}$ \\
\hline III & $\begin{array}{l}\text { Outros trabalhadores de saúde que atuam } \\
\text { na ESF (médicos, enfermeiros, técnicos de } \\
\text { enfermagem, agentes comunitários de saúde, } \\
\text { agentes administrativos). }\end{array}$ & $\begin{array}{l}\text { Grupo que faz a interface com as } \\
\text { equipes de saúde bucal. }\end{array}$ \\
\hline Usuários do sistema & $\begin{array}{l}\text { Representa o centro do processo } \\
\text { de atenção em saúde e, assim, } \\
\text { pode emitir suas impressões sobre } \\
\text { as práticas de saúde bucal. }\end{array}$ \\
\hline IV & $\begin{array}{l}\text { Informantes-chave (Coordenador da Atenção } \\
\text { Básica, Coordenador do Programa de Saúde } \\
\text { na Escola, Coordenador de Saúde Bucal, } \\
\text { representante do Conselho Municipal de } \\
\text { Saúde, responsáveis pelo serviço de referência, } \\
\text { atuantes no período histórico do estudo). }\end{array}$ & $\begin{array}{l}\text { Possibilita a coleta de informações } \\
\text { complementares e fundamentais } \\
\text { ao desenvolvimento das análises } \\
\text { das condições das práticas de } \\
\text { saúde bucal. }\end{array}$ \\
\hline
\end{tabular}

Fonte: elaborado pelos autores

Para apresentação dos resultados, os participantes foram identificados pela letra E, numerados de acordo com o grupo (exemplo: E1.Grupol ou E1.GrupolI). Os nomes dos bairros ou áreas citados nas falas inseridas neste trabalho foram substituídos pelas letras A, B, C e D para garantir o sigilo da identidade dos entrevistados.

A coleta de dados se deu a partir de entrevista semiestruturada com roteiro orientador para todos os grupos, abordando os dispositivos que orientam a prática em saúde bucal na ESF (acolhimento, vínculo, autonomia, responsabilização, resolubilidade, relações estabelecidas entre sujeitos sociais, caracterização do munícipio e organização da gestão). As entrevistas foram realizadas em ambiente reservado, apenas com a

presença do entrevistado e do entrevistador. Quando necessário, as informações adquiridas nas entrevistas foram complementadas por dados obtidos a partir de consulta a documentos, relatórios e portarias referentes ao trabalho das Equipes de Saúde Bucal.

A seleção dos participantes baseou-se no princípio da saturação, em que se determina a amostra no momento em que as falas se repetem e não acrescentam mais informações, ou quando o número de indivíduos se esgota ${ }^{19}$. Ao final foram realizadas 29 entrevistas, sete no grupo I, 11 no grupo II, seis no grupo III e cinco no grupo IV. 
Para análise do material coletado e melhor entendimento das questões deste estudo, foi utilizada a análise hermenêutica-dialética, proposta por Minayo ${ }^{20}$. A hermenêutica pressupõe o ser humano marcado pelo tempo e espaço em que vive, e tem a linguagem como núcleo central, reflexo do seu momento histórico. A dialética, por sua vez, busca apreender as contradições na linguagem a partir da crítica e, assim, compreender as relações e as práticas sociais. A união da hermenêutica com a dialética leva o intérprete a entender o texto, a fala, o depoimento, como resultado de um processo social e de conhecimento, fruto de múltiplas determinações, mas com significado específico ${ }^{20}$.

$\mathrm{Na}$ análise realizamos os seguintes passos:

- 1 - Ordenação dos dados: refere-se ao primeiro contato com o material empírico coletado. Este momento envolveu a transcrição das gravações, leitura geral do material transcrito, organização dos diferentes dados contemplados nas entrevistas e nos documentos.

- 2 - Classificação dos dados: os dados empíricos foram classificados a partir dos objetivos e pressupostos teóricos da pesquisa. Esta fase constou de duas etapas:

o Etapa I - compreendeu a leitura exaustiva do material coletado nas entrevistas na busca de estabelecer núcleos de sentido fundamentados nos seguintes dispositivos: acolhimento, vínculo, autonomia, responsabilização, resolutividade e organização da prática. Nas entrevistas, recortamos as falas correspondentes aos núcleos de sentido e, em seguida, montamos um quadro para cada grupo de entrevistados e confrontamos núcleos de sentido por grupo.

o Etapa II - nesta etapa deu-se a procura pelo confronto entre os diferentes grupos, através das convergências, divergências, diferenças e complementaridades, a fim de construirmos/reconstruirmos as categorias empíricas do estudo.

- 3 - Análise final: realizamos o entrecruzamento entre as diferentes informações coletadas nas entrevistas, fazendo o confronto entre as falas dos participantes, agrupando as ideias convergentes, divergentes, complementares e diferentes. Em seguida, discutimos os resultados, tendo como referência as categorias empíricas e o referencial teórico.

\section{RESULTADOS E DISCUSSÃO}

Após análise das entrevistas coletadas, realizamos a classificação das categorias empíricas em três grandes grupos: Organização do serviço de saúde e resolubilidade 
das ações, Forma de contratação e rotatividade da ESB e Influência da burocracia e do financiamento na estrutura do serviço de saúde.

\section{Organização do serviço de saúde e resolubilidade das ações}

O município estudado possui em sua rede de Atenção à Saúde, segundo o Relatório Anual da Gestão de 2014²1, 12 Unidades Básicas de Saúde, contando com 15 equipes da ESF. No município também funcionam nove ESB (modalidade I), cinco Unidades Satélites e duas equipes do Núcleo de Apoio à Saúde da Família (NASF).

A cobertura da ESF compreende $78 \%$ da população, porém na área de saúde bucal é de apenas 50\%, o que leva à existência de uma demanda reprimida e à superlotação das unidades, pois as pessoas residentes em áreas descobertas buscam atendimento nas unidades que possuem CD, conforme declararam o E4.Grupol e o E5.Grupoll.

"Então essa unidade atende o bairro $A$ todo, só que, além do bairro $A$, tem uma unidade que está sem atendimento odontológico. Então, nós atendemos também eles aqui, que é o bairro B, e nós atendemos uma demanda bem grande devido a juntar essas duas áreas." (E4.Grupol).

"[...], mas ele acaba atendendo outras áreas como a C e a D porque também está sem dentista para atender." (E5.Grupoll).

Ao discutir essa questão, Ribeiro-Sobrinho et al. ${ }^{22}$ entendem que a oferta de serviços odontológicos de forma desigual é consequência do modelo assistencial privatista que predomina no Brasil, aliado à desigualdade socioeconômica, má distribuição dos profissionais de saúde, baixa capacidade instalada e financiamento irregular.

Apesar da relação desproporcional entre ESB e EqSF, um dos participantes da pesquisa relata que por mais que exista uma alta demanda por serviços odontológicos, a unidade não reprime o fluxo de usuários e busca formas de atender à necessidade do paciente. Destaca também a importância do agente Comunitário de Saúde para facilitar o elo entre o serviço e a comunidade, tornando-se responsável por informar e encaminhar o paciente à unidade de saúde para atendimento odontológico.

"A demanda é grande, mas a gente não reprime demanda. Na marcação, na segunda mesmo da marcação, a gente consegue atender a todos. Nunca é... difícil sobrar gente. Quando sobra gente, a gente sempre faz um acolhimento, pra tentar já deixar marcado, se não der, se não for uma urgência, a gente explica: 'Segunda tem!' Mas é difícil, sempre sobra vaga. É tanto que quando sobra, a gente entra em contato com os Agentes Comunitários de Saúde, eles mandam a mais que a quantidade $[\ldots .$.$] " (E6.GrupolI).$

O município conta ainda com um Centro de Especialidades Odontológicas (CEO) e um Laboratório de Prótese Dentária. O CEO é do tipo I, composto por dois consultórios e dois CD. São disponibilizados serviços de endodontia, cirurgia oral menor de tecidos duros e radiografias para os pacientes encaminhados pelo $C D$ da 
unidade básica de saúde, mas apesar de considerado modalidade I, não oferece os serviços de periodontia especializada, cirurgia oral menor dos tecidos moles e atendimento aos portadores de necessidades especiais conforme rege a Portaria № 599/GM, de 23 de março de $2006^{23}$.

Em relação aos procedimentos realizados pelos CD na Atenção Básica, foi possível perceber que a maioria realiza exodontia simples, restauração, profilaxia e aplicação tópica de flúor. Apenas um profissional relatou fazer capeamento pulpar. Endodontia, radiografia e exodontia mais complexas são referenciadas para o CEO. Quando o paciente tem alguma outra necessidade que a unidade de saúde não possui suporte para resolver, encaminha-o para que a Secretaria de Saúde solucione o problema.

"[...] aqui quando chega um procedimento mais complicado, aí fazer um tratamento de canal, a gente encaminha pro CEO. Aqui a gente faz limpeza, extração simples, restauração, aplicação de flúor... é basicamente." (E2.grupol, E3.Grupol).

"A não ser que seja uma cirurgia complexa, mais maxilofacial, aí a gente pede para o paciente se encaminhar à Secretaria de Saúde, que é para, a partir daí o secretário averiguar se pode enviar para algum lugar ou não, a partir do secretário... faz um requerimento, uma solicitação, e informa o caso do paciente." (E7.Grupol).

Os relatos que se referem aos encaminhamentos para O CEO ou Secretaria de Saúde mostram que existe uma preocupação com a resolubilidade por parte dos profissionais ao tentarem solucionar as necessidades dos pacientes. Costa et al. ${ }^{1}$ ressaltaram essa questão, ao colocar a importância de uma visão não fragmentada do indivíduo, procurando enxergá-lo de forma integral e resolver as suas demandas em todos os níveis de atenção.

A forma de marcação da primeira consulta, como pode ser visto nos discursos a seguir, não é a mesma em todas as unidades de saúde, com maior prevalência de marcação por meio da demanda espontânea, sem organização da oferta por linhas de cuidado. Esta situação corrobora com os achados de Tavares et al. ${ }^{8}$ e, para Rodrigues e Bomfim ${ }^{24}$, esse tipo de marcação "se torna excludente", pois não tem como base as necessidades da população adstrita.

\footnotetext{
"Não, tem que marcar de novo no final do mês. A única marcação que fica fixa é do Agente Comunitário de Saúde, que cada área, essa microrregião que te falei, ela vai ficar responsável por um turno no mês, aí ela já manda os oito pacientes anotados. Pra gente, são as únicas pessoas que não vêm marcar." (E3.Grupol).

"A cada final de tratamento surgem vagas semanais, fazemos marcação semanal. Então esse surgimento de vagas, nós fazemos a marcação de pacientes novos e, assim, sucessivamente." (E4.Grupol).
}

"Ele volta na segunda-feira de novo e marca [...]" (E5.Grupol). 
Esse resultado corrobora com estudo de Pimentel et al. ${ }^{14}$ realizado em 2012 no estado de Pernambuco, cuja maior frequência de marcação encontrada em municípios de pequeno porte foi por microárea com intermediação dos ACS.

Os achados contrariam orientação do Ministério da Saúde ${ }^{25}$ quanto ao critério para definir o atendimento, que deve ser conduzido pela gravidade ou sofrimento do usuário e, não somente pela ordem de chegada. Em apenas uma unidade de saúde, onde existe um turno semanal destinado para pacientes especiais e outro para crianças triadas pelo Programa de Saúde na Escola (PSE), foi relatado o atendimento por prioridades.

“[...] a não ser que seja um paciente que tenha necessidades especiais, por exemplo, na quinta-feira à tarde, eu tenho alguns pacientes que eu já deixo marcado toda semana, então eles não precisam vir buscar a ficha para serem atendidos. Os do PSE são na quarta-feira." (E5. Grupol).

O número de vagas ofertado para atendimento pelos $C D$, conforme depoimento a seguir, é de oito por turno com mais duas vagas para atendimento de urgência: "Nossa marcação é assim, nós fazemos atendimento de oito pacientes por tuno e duas emergências, que são a demanda espontânea" (E3.Grupol e E4.Grupol).

No entanto, foi possível constatar que a maioria das pessoas que buscam por atendimento não consegue a garantia da continuidade do tratamento, pois o usuário que é atendido entra na fila outra vez para agendar nova consulta. Dessa forma, apesar de gerar uma maior rotatividade de usuários no serviço, possui uma baixa resolubilidade, pois os pacientes continuam sem resolver a sua queixa ${ }^{13,24}$.

Em algumas unidades a maneira de atuação é diferente, o profissional diz concluir o tratamento do paciente antes de abrir uma nova vaga ou, se apresentar muitas necessidades, já deixa agendado. Outro fator citado foi que a cada marcação de consulta, apenas um membro da família poderá receber atendimento.

“[...] eu só sei que por casa só pode atender uma pessoa mesmo, no mês. No caso eu fui atendida agora, se eu quiser trazer minha filha agora não posso, só no outro mês [...]" (E4.GrupollI).

"Alguns têm a data fixa, são aqueles que a gente vê que tem mais necessidades, a gente remarca. Mas os outros, eles entram na fila pra pegar também uma nova ficha." (E2.Grupol).

Isso evidencia que a organização do serviço não garante a resolução dos problemas demandados pelos usuários. Os pacientes que vão arriscar um novo atendimento precisam de tempo disponível para novas marcações sem poder fazer um planejamento pessoal com possibilidade de conciliar trabalho, família, lazer e cuidados com a saúde. Assim, há necessidade de ver o indivíduo como um ser social envolto por obrigações, que muitas vezes precisa optar pela sua sobrevivência, deixando para procurar o serviço de saúde mediante a presença de dor. 
"[...] eu gostei do que ele fez no procedimento e eu fui marcando e tal, mas só que se fosse para primeira vez e ele já marcar tudo que a gente tivesse que fazer e já deixar certo, era melhor, você não tinha o tempo de ficar indo lá marcar direto, entendeu?" (E6.GrupolII).

Diante disso, o que leva a continuidade dessa realidade? Qual o papel da gestão frente às necessidades dos usuários com a forma de organização vigente? Será que as ações estão centradas prioritariamente na resolução das demandas apresentadas pela população ou apenas na oferta de um serviço paliativo?

A não resolução dos problemas da população e a continuidade das queixas, segundo $\operatorname{Costa}^{26}$ e Andrade ${ }^{27}$, ocorrem pela reprodução do modelo tradicional, centrado na doença, e a grande demanda reprimida. Porém, apesar da alta demanda e do tempo de espera para atendimento no CEO, alguns entrevistados concordam que o município vem melhorando a infraestrutura, oferecendo maior suporte para atendimento.

"Eu acho que a saúde ficou mais próxima do povo né, quem realmente precisava tá sendo atendido. [...] O posto hoje tem outra estrutura, né?! $\mathrm{O}$ atendimento é outro. [..] Tem o carro da saúde, tem atendimento praticamente vinte quatros horas, precisou, liga e já pede, sabe?! E eles atendem toda demanda do município... [...] Tudo que precisa se for cirurgia distante né, tem uma possibilidade dos recursos." (E3. GrupollI).

"[...] Porque renovou o posto, era todo acabado. [...], mas eu acho que está melhor, porque aquele estava muito acabado, muito malacabado, e agora está tudo renovado... televisão, não tinha nada, não tinha." (E2.GrupollI).

A contrarreferência não funciona na odontologia. $O$ paciente que é encaminhado pelo $C D$ para outro serviço, como o CEO, não retorna ou retorna por conta própria quando carece de outros procedimentos: "Retorna, mas não encaminhados por contra referência. Eles vêm por conta própria porque têm outros problemas" (E5.Grupol).

Essa realidade também é mencionada por Pimentel et al. ${ }^{28}$, em um estudo realizado no Distrito Sanitário $\mathrm{VI}$, Recife (PE), onde é um fato comum a ausência do retorno do usuário à unidade por meio da contrarreferência. No entanto, aborda que o profissional ao finalizar o tratamento do paciente deve encaminhá-lo por meio da contrarreferência para a unidade de origem, constando a identificação do profissional, diagnóstico e o tratamento que foi realizado.

Nesta pesquisa, alguns profissionais tentam encaminhar os pacientes para o CEO para fazer endodontia, mas devido à demora no atendimento, muitos usuários optam pela exodontia. Por mais que o CD aborde os benefícios do tratamento, o descrédito no atendimento leva a não adesão ao plano de tratamento apresentado, pois a decisão do paciente em optar por um tratamento conservador muitas das vezes está condicionada a experiência e relatos sobre a demora em executá-lo. 


\begin{abstract}
"Assim, porque... quando você vai... imagina aí, um profissional pra atender um município, vamos dizer de 70 mil habitantes, um endodontista, entendeu? [...] aí demora quatro meses pra fazer o procedimento, nesse meio tempo o paciente já fez a extração, ou nesse meio tempo, o dente já quebrou, entendeu? [...] alguns pacientes, até mesmo de encaminhar pra lá e chegar aqui pra fazer outro procedimento e sem já os dentes na boca 'ah doutor, doeu muito, não sei o que... fui em uma... na clínica popular e fiz a extração'." (E3. Grupol).
\end{abstract}

Ao serem questionados sobre o trabalho extramuros, os CD disseram não realizar visita domiciliar, o que fragiliza o processo de trabalho, pois esta é uma ação que visa à aproximação do profissional com a comunidade e fortalecimento do vínculo a partir da utilização da tecnologia leve ${ }^{1,26}$, além de ser um momento oportuno para resolver algum problema do paciente impossibilitado de comparecer à unidade de saúde em busca de atendimento ${ }^{23}$. Nesse sentido, Barros et al. ${ }^{29}$ reforçam essa atividade por ir além do atendimento e ter como objetivo a promoção, manutenção e recuperação da saúde na perspectiva da família ao ver o indivíduo no âmbito biopsicossocial, e não mais centrado na doença.

"Por parte do dentista não, mas toda quinta-feira à tarde o médico e a enfermeira saem pra fazer visita." (E2 e E5.Grupol).

As necessidades dos usuários devem ser discutidas e negociadas, de forma que a lógica de produção de demandas seja articulada com os serviços disponíveis, pois muitas vezes os usuários têm equívocos sobre os procedimentos que serão realizados ${ }^{5}$.

Grande parte das ações de educação em saúde desenvolvida pela maioria dos profissionais entrevistados faz parte das atividades do PSE e são realizadas uma vez por ano. Esta intervenção é insuficiente para atingir os objetivos deste programa, no que diz respeito à promoção de saúde com reforço para prevenções de agravos e o enfrentamento das vulnerabilidades que comprometam o desenvolvimento escolar, pois sua frequência é baixa, não contribuindo de forma efetiva para a construção de autonomia e corresponsabilização dos indivíduos por sua saúde.

"A gente trabalha com o PSE né? Então, ele já foi esse ano, já fez esse trabalho em todas as escolas que pertencem a nossa unidade. [...]. A gente tenta fazer né, sala de espera relacionada a isso, trabalhar com os agentes, mas o foco maior é nas escolas [...]" (E6.Grupoll).

"Mas na verdade não adianta você ir lá uma vez por ano, digamos, entendo, a gente chega lá uma pessoa de branco, criança de sete e oito anos que, sabe né? Naquela danação toda, você chegar e falar, às vezes não presta atenção, entendeu? [...] deveria ser uma coisa mais constante [...]" (E3.Grpol).

Esses achados corroboram com Pimentel et al. ${ }^{14}$, quando afirmam que embora as equipes participem nos grupos educativos - gestantes, idosos, hipertensos e diabéticos -, a articulação com a comunidade necessita de avanços, pois a integração com instituições 
locais ainda está muito focada nas escolas, privando as equipes de outras formas de participação comunitária.

Apesar de as ações de educação em saúde, em geral, serem pontuais, existem profissionais que se esforçam para garantir atividades semanais nas próprias unidades.

\begin{abstract}
"Sempre acontece. Hoje mesmo aconteceu palestra para os profissionais da área, inclusive a ACS e agentes de endemias, falando sobre o câncer bucal. Quando não tem com profissionais ele sempre faz com pacientes salas de espera. Ele e a assistente de odonto também fazem. [...] então em cada semana um profissional atua em uma área com determinado tema. Então cada semana a gente entra com um profissional diferente." (E4.Grupoll).
\end{abstract}

Os relatos ainda mostraram que a frequência dessas atividades no município vem aumentando, como pode ser observado a seguir:

"Mas a gente tem visto a parte de educação em saúde acontecendo um pouco mais. A parte de promoção, prevenção ela tem acontecido um pouco mais, porque a gente não tinha dado nenhum de que isso acontecia [...] os profissionais estão mais assíduos, né?" (E1.GrupoIV).

As atividades coletivas que acontecem fora do ambiente clínico, permitem ao profissional de saúde conhecer a dinâmica da comunidade, assim como, promover maior aproximação com as pessoas de sua área de abrangência ${ }^{1}$.

Um problema citado por um dos entrevistados ao abordar a educação em saúde é que a população não entende a importância das atividades voltadas para promoção e prevenção, valorizando apenas o atendimento no consultório. Na opinião de Pimentel et al. ${ }^{28}$, isso também ocorre com os trabalhadores, como é o caso dos próprios gerentes das USF que relacionam o trabalho do CD apenas ao ambiente clínico, e contribui para a continuidade da prática curativista sem atingir melhorias na condição de saúde bucal da população.

"[...] que às vezes o paciente acha assim: se eu não tô aqui trabalhando, eu não estou trabalhando entendeu? Se às vezes eu posso tá fazendo a minha palestra, que eu faço nas escolas que eu falo sobre alimentação, escovação, eles acham que eu não estou trabalhando porque eu não estou aqui atendendo [...]" (E4.Grupol).

Para Andrade ${ }^{30}$, essa maneira de ver a odontologia é um reflexo histórico da forma como a mesma foi criada, centrada no diagnóstico e em procedimentos invasivos. Para o autor, esta situação dificulta a compreensão sobre a importância da pratica odontológica com base nos aspectos das políticas de saúde pública ou como parte da produção de saúde geral/bucal com maior abrangência e impacto nos índices epidemiológicos.

Ao serem questionados sobre a relação entre as coordenações da Atenção Básica e de Saúde Bucal com as equipes de saúde para resolução conjunta dos problemas, os profissionais apontam como positiva. A articulação com a gestão é fundamental para a organização do serviço e obtenção de melhores resultados na produção do cuidado, pois 
todos os profissionais são responsáveis pela qualidade da atenção, apesar de atuarem em setores diferentes.

Para tanto, também é indispensável uma formação profissional adequada. Mattos et al. ${ }^{7}$ argumentam que a formação profissional tem sido um dos entraves para a execução do trabalho coletivo, visto que essa forma de atuar não é abordada nos processos pedagógicos da área de saúde, na maioria das universidades, ou o é de forma pontual e isolada.

Na compreensão de Faccin et al. ${ }^{31}$, a ruptura do modelo hegemônico, voltado para a prática individual e fragmentada dar-se-á a partir de mudanças nas diretrizes curriculares, nos cursos de pós-graduação e por meio da educação permanente. Questão que deve ser pensada, visto que grande parte dos recém-formados tem o serviço público como primeiro meio de acesso ao mercado de trabalho, mas que sai da graduação sem receber uma formação apropriada para atuar no SUS.

Contrariando essa tendência, este estudo revelou profissionais jovens envolvidos com o processo de produção de saúde e preocupados com a garantia do cuidado. Para um dos entrevistados, o problema está nos profissionais que atuam há mais tempo no serviço, por terem um olhar restrito ao atendimento clínico.

"É, eu percebo que alguns mais antigos (se refere aos dentistas da rede), eles não têm, eles não têm muito bem esse conceito de saúde coletiva na cabeça, sabe? Eles são muito assistenciais. Eles chegam, atendem e vão embora. [...] eles não se preocupam com a integralidade do serviço sabe? [...] E por sorte a equipe de dentistas daqui, do município todo, é de dentistas mais jovens, [...], mas a maioria é mais jovem. É o pessoal que já tá vindo da UEFS, da UFBA entendeu? Que já vêm com essa cabeça de saúde coletiva." (E5.Grupol).

Rodrigues $^{32}$, ao investigar o processo de trabalho da ESB, ressaltou que a educação permanente "possibilita a agregação entre aprendizado, reflexão crítica sobre o trabalho, resolutividade da clínica e promoção da saúde coletiva"32:180. Contudo, não existe no município ações neste sentido, mesmo com os profissionais de saúde ressaltando a importância da aprendizagem continuada para qualificação das equipes.

“Não! Eu sei que o que a gente sempre cobra nas reuniões [...] que a gente tenha uma educação permanente. Sempre é bom se qualificar né? Mas desde que eu entrei, nas gestões passadas, também não houve [...] educação permanente não houve." (E2.Grupol).

“[...] muitas vezes a gente vem pra cá e não é orientado como se deve fazer na saúde pública, porque a gente tem na faculdade, mas não é o que é realmente aqui. Eu acho que a gente deveria ter uma reciclagem sobre isso [...] cursos pra orientar, outras maneiras que se pode trabalhar aqui no PSF, entendeu? [...] Fazer cursos, não só com os profissionais, mas também com os gestores pra eles entenderem que precisa também ter essa outra parte da odontologia [...]" (E4.Grupol). 
Quanto ao período de trabalho, apesar de os relatos explicitarem que os CD estão cumprindo a carga horária de 40 horas, a grande maioria atua no setor privado. Condição que interfere na comunicação entre a coordenação de saúde bucal e os profissionais que atuam na rede, embora a dupla jornada não seja questionada pelo município, desde que o profissional cumpra o número de atendimentos diários estabelecidos pela gestão.

"Com relação à carga horária, e cumprimento das atividades, um pouco mais, mas sinceramente é a classe que eu tenho mais trabalho [...] Porque geralmente, às vezes, o profissional tem um [...] consultório, então ele quer ir para o consultório e isso tem dificuldade." (E5.GrupolV).

"[...] marcaram a reunião, mas marcou depois do atendimento, e aí nem todos vão, entendeu? Porque se eu tenho um paciente marcado quatro horas na minha clínica, como é que eu vou sair daqui três horas, três e meia e o vou pra uma reunião com o paciente marcado lá, entendeu? Então nem todos que tem consultório particular, que acho que são $90 \%$ dos profissionais, foram pra reunião, justamente por esse motivo [...] 40 horas na verdade no papel, entendeu? No papel." (E3.Grupol).

Essa situação nos leva a refletir se, ao atender oito pacientes por turno mais duas emergências no setor público e ainda atuar no setor privado, o profissional consegue desenvolver um trabalho de qualidade, fundamentado na produção do cuidado. Será que existe realmente uma visão integral do sujeito? Qual o contexto político, social e econômico a que o CD está submetido e como isso condiciona ou interfere nas suas ações?

Sobre a periodicidade das reuniões com a coordenação de saúde bucal para planejamento das ações, houve divergência entre os entrevistados sobre a frequência com que os encontros são realizados:

"Geralmente a gente faz reuniões é, com a coordenação. A gente sempre faz uma reunião de três em três meses." (E2.Grupol).

"Pelo que eu percebi fazem duas por ano, uma no primeiro semestre uma no segundo semestre. Eu só peguei a do segundo semestre, porque quando eu entrei já tinham feito." (E5.Grupol).

Ainda com relação às reuniões, os relatos mostraram que acontecem com intuito de passar as metas do município para saúde bucal e tratar as queixas e problemas que ocorrem nas unidades.

"[...] pelo fato de [...] que a gente como sentava lá pra reunir, era pra você dizer sua opinião em relação ao atendimento e depois você dizer suas queixas em relação à infraestrutura, material [...] Hoje em dia não tem mais, é tanto que a última reunião que teve, foi uma solicitação mais nossa, e eu acho que $90 \%$ do tema abordado foi o técnico [...]" (E3.Grupol). 
Ao se considerar a resolubilidade como decorrente das ações integradas, um fator indispensável a ser discutido é a forma como são organizadas. As práticas devem promover a interação entre vários profissionais de diferentes formações, que busquem, com suas atuações, complementar os saberes e resolver os problemas da comunidade a partir de um planejamento baseado nos determinantes do processo saúde-doença ${ }^{1}$.

É interessante também ressaltar a importância do acompanhamento das equipes pelo coordenador de saúde bucal, que tem a responsabilidade de organizar o modelo de atenção à saúde bucal do município e orientar as equipes quanto às suas responsabilidades e ao cumprimento dos princípios e diretrizes do SUS na ESF ${ }^{14}$.

$A$ inserção do $C D$ em equipe multiprofissional foi um desafio para o trabalho no contexto de modelo de atenção no qual as práticas conservadoras eram hegemônicas ${ }^{22,24}$.

Ao analisarmos o trabalho em equipe no município investigado, constatamos que em algumas unidades ainda existe uma desvinculação entre a ESB e EqSF, um profissional desconhece o trabalho desenvolvido pelo outro, apesar de atuarem no mesmo espaço. Todavia, algumas falas remetem a importância da integralidade nas ações, a partir da realização do planejamento, com discussão de casos entres os profissionais e elaboração das ações de educação em saúde coletivamente.

"Eu acho que a necessidade do povo é que a equipe trabalhe em equipe. [...] Tem alguns pacientes que precisam de uma avaliação do caso a ser do dentista e do médico, ele vem na minha sala ou eu vou à dele. A gente discute o caso sobre o tratamento, se assim pode ou não fazer a cirurgia, se pode extrair o dente ou não, se o paciente sofre de alguma patologia crônica, se está descompensado." (E2.Grupoll).

Mediante as análises, foi possível perceber que a organização do serviço de saúde bucal no município encontra-se centrada no $C D$, que não possui o conhecimento prévio das necessidades dos usuários, não existe uma política de educação em saúde que aponte mudanças dessa realidade. Também podemos afirmar que o município ainda não conseguiu garantir a resolubilidade dos problemas de saúde, pois a presença da integralidade na atuação da maioria dos profissionais não foi expressiva, com pouca presença de trabalho em equipe, falta de planejamento interdisciplinar, além da fragilidade no processo de referência e contra referência.

\section{Forma de contratação e rotatividade da ESB}

Como ocorre em outros estudos realizados na Bahia e no Brasil ${ }^{7,24,26,33}$, a contratação dos profissionais é delegada pelo município a uma cooperativa. O CD não possui vínculo empregatício com o município sendo a precarização uma questão predominante em virtude da vinculação e contratação dos trabalhadores para as ESB.

A justificativa para a não realização de concurso público são os limites impostos pela Lei de Responsabilidade Fiscal, que regulamenta as normas de financiamento público 
voltadas para a responsabilidade na gestão fiscal, inclusive na geração de despesas com pessoal e restringe os recursos municipais para a contratação de trabalhadores, para o aumento dos salários e não amplia os serviços e gratificações. A pesquisa mostrou que esta condição dificulta a ampliação do serviço.

"[...] e eu tenho a Lei de Responsabilidade Fiscal que me engessa, em todos os aspectos [...]. É muito complicado, hoje, se trabalhar gestão pública e saúde pública com uma lei de responsabilidade fiscal que te trava o tempo inteiro [...]" (E1.GrupoIV).

"[...], mas o prefeito é impossibilitado de fazer, contratar e concurso. [...]. Então, [...] por causa da 141, na Lei de Responsabilidade Fiscal, ele é impossibilitado de fazer concurso, aí a gente não consegue ampliar nada. [...] não se contrata uma agulha no município por causa disso." (E3.GrupolV).

Quando questionados sobre os direitos trabalhistas dos profissionais, percebemos que não são garantidos quando a contratação ocorre por meio de cooperativa. Essa situação, na visão da gestão, gera "prejuízo" para o CD que não possui seus direitos assegurados. Existe uma política informal na garantia de emprego e da regularidade salarial do profissional, muitas vezes pelas influências, pressões e interferências políticas por conta dos interesses e da vontade dos contratantes ${ }^{34}$.

"[...] todos os direitos de um trabalho precário. [...], mas na área de saúde os níveis superiores é muito complicada essa questão da desprecarização de vínculo, porque gera um custo muito alto para o município. Enquanto a saúde e programas ministeriais continuarem incidindo em índice pessoal, a saúde vai ter muita dificuldade de desprecarizar profissional e de criar esse vínculo que é legal." (E3. GrupolV).

Discutindo a questão do vínculo trabalhista, Gonçalves e Ramos ${ }^{33}$ citaram a curta permanência ou a falta do CD nas unidades como decorrente da forma de contratação, um problema para o bom funcionamento da EqSF, que gera insegurança para os trabalhadores e compromete a atenção aos usuários.

Como justificativa para o não cumprimento da jornada de trabalho determinada pelo Ministério da Saúde, alguns participantes relatam que a remuneração é baixa, tornando-se necessários outros vínculos profissionais, principalmente em consultórios particulares. Segundo Costa et al. ${ }^{26}$, a ESF não oferece estabilidade ao trabalhador, pois há precarização na contratação em alguns municípios, não havendo concurso público ou seleção, o que lhe possibilita atuar em outros campos além da ESF, muitas vezes como forma de complementação salarial. Situação definida por Chaves e Silva ${ }^{35}$ como "dupla militância ou dupla inserção".

A presença do profissional no campo privado influencia na prática clínica individual do $C D$, em que a lógica do subcampo privado está presente em diversos momentos nas unidades públicas de saúde, ou seja, no SUS, produzindo a perpetuação da prática 
curativista nas atividades dos seus agentes. Faz-se necessário um esforço extra para a manutenção das mudanças na prática profissional no setor público, contribuindo para sua maior efetividade ${ }^{35}$.

"[...] o nosso salário ficou defasado durante anos. Entendeu? [...] é difícil um profissional manter essas quarenta horas dentro de um posto, entendeu? Você chegar as oito, trabalhar até ás doze, dá uma as cinco, entendeu? Como teoricamente tá no papel, porque primeiro pelo salário, um profissional acho que não vai sobreviver só com o salário do PSF, pelo fato do valor que pagam [...]" (E3.Grupol).

A rotatividade do $C D$ foi declarada por um dos entrevistados, como baixa, devido à maioria dos profissionais residirem no município e possuírem consultório particular. Para ele, o compromisso dos profissionais atuais com o serviço público reflete a baixa rotatividade.

\footnotetext{
“Não, aqui é tranquilo, aqui não tem muita rotatividade não. [...] $\mathrm{A}$ equipe que chegou agora é uma equipe comprometida, é uma equipe que tá fazendo saúde pública acontecer mesmo, e assim, a gente já está vendo o diferencial [...]" (E2.GrupoIV).
}

As questões trazidas acima nos permitem questionar: será que o principal fator para a baixa rotatividade do profissional é o compromisso com o serviço ou o trabalho na EqSF visa garantir uma complementação salarial?

A responsabilidade com o serviço, conforme a portaria $n=2.488$, de 21 de outubro de 2011, que normatiza o processo de trabalho do CD na ESF, vai além do atendimento clínico, cabendo ao profissional compartilhar as atribuições da unidade de saúde com a própria equipe e EqSF, coordenar e realizar atividade de caráter educativo no âmbito individual e coletivo de maneira multidisciplinar e interdisciplinar, além de contribuir e participar das atividades de educação permanente ${ }^{25}$.

Após análise dos resultados, notamos que a informalidade no vínculo profissional e a baixa remuneração levam a precarização na assistência e a desvalorização do $C D$, o que pode interferir no processo de trabalho e comprometer a atenção em saúde.

Influência da burocracia e do financiamento na estrutura do serviço de saúde O repasse financeiro para o município é do tipo fundo a fundo, diretamente do Fundo Nacional de Saúde. As ações de saúde bucal são financiadas com recursos da União, próprios ou de outras fontes suplementares de financiamento, observadas as condições de gestão, a qualificação e a certificação dos programas e incentivos do Ministério da Saúde e os respectivos tetos financeiros ${ }^{36}$.

"[...] O que acontece, a cidade tem acima de 50 mil habitantes, eu recebo por equipe de saúde da família $\mathrm{R} \$ 7.130,00$. A cidade vizinha, como tem menos de 50 mil recebe $\mathrm{R} \$ 10.150,00$, já é pouco! Mas a cidade maior é, 7 mil é inviável. Você tem um custo médio, hoje, com a equipe de saúde da família de $\mathrm{R} \$ 30.000,00$, você recebe 7 mil, gasta 30 quando a lei permite que você só gaste $51 \%$. Com saúde bucal não é muito diferente, por saldo cada equipe é em média de dois mil e 
poucos reais, não custeia nem o profissional dentista, ainda mais o custo de material, tem o auxiliar de saúde bucal, né? É a contrapartida! [...]" (E1.GrupolV).

$\mathrm{Na}$ opinião de alguns entrevistados, é grande a necessidade de financiamento, o que é repassado não consegue suprir todas as prerrogativas do programa de saúde bucal. Por conta dessa situação, os gestores encontram dificuldade para determinação dos gastos e a adequada gestão dos limitados recursos disponíveis ${ }^{37}$.

Existe uma incongruência em relação ao financiamento na saúde bucal e as necessidades para o adequado funcionamento do serviço. $O$ incentivo financeiro anual do Fundo Nacional de Saúde, para as Equipes de Saúde Bucal modalidade I, definido pela Portaria $n^{\circ}$ 673/GM de 8 de junho de 2003 é de $R \$ 15.600$ (quinze mil e seiscentos reais). Percebemos, por meio dos relatos, que a quantia repassada não é suficiente para resolução dos problemas da atenção em saúde.

"[...] os municípios são obrigados a gastar $15 \%$ da sua receita com a saúde e a gente gasta em média 19, 20 e vinte e pouco e eu desafio qualquer município a gastar menos que 20. A maior parcela está na conta do município mesmo, principalmente para atenção básica [...]" (E3.GrupolV).

O repasse de recursos conforme o tipo de equipe, sem levar em conta as condições dos municípios, é a melhor forma de garantir a equidade no cuidado em saúde, ou existe o favorecimento de determinadas localidades em detrimento de outras? O princípio da equidade é exercido corretamente?

Para Antunes e Narvai ${ }^{38}$, o surgimento de desigualdades evitáveis e desnecessárias em saúde deve-se à existência de grupos com melhores condições socioeconômicas e maior favorecimento das vantagens de políticas públicas. Contudo, esta situação pode ser modificada com a utilização de estratégias que beneficiem diretamente as áreas com maiores necessidades.

Os entraves burocráticos para gestão financeira e organização do serviço, envolvendo os processos de instalação e financiamento das equipes, de contratação profissional, da manutenção e solicitação dos equipamentos, dificultam a resolubilidade das ações no serviço público.

Alguns dos entrevistados, principalmente os $C D$, expressaram insatisfação com a tecnologia dura, afirmando que muitos equipamentos estão "obsoletos" e apresentam recorrentes defeitos, principalmente a cadeira odontológica, o que compromete a rotina de atendimento dos pacientes. Ausência de equipamentos de radiologia nas unidades, a insuficiente quantidade de instrumentais e a demora na chegada de materiais de consumo são outras dificuldades para os participantes deste estudo, cuja justificativa é a falta de dinheiro. Gonçalves e Ramos ${ }^{33}$ e Chaves e Miranda ${ }^{34}$ constataram em seus estudos, que esse problema compromete o processo de trabalho dos profissionais. Faccin et al. ${ }^{31}$ acrescentam que a ausência de condições 
adequadas pode restringir as competências do profissional, estabelecidas pela ESF, estagnando e interferindo nas suas ações.

"Às vezes tem a questão financeira do próprio município, que às vezes não tem condições ter outro profissional. Burocracia mesmo de coisas de prefeitura, às vezes a gente não pode atender porque não tem material, mas o material já foi solicitado, mas tá travado lá na licitação e às vezes não consegue liberar, essas coisinhas. Assim, coisas de burocracia mesmo de Prefeitura e às vezes falta de dinheiro mesmo." (E1.Grupol).

A insuficiência e a dificuldade de gestão dos recursos financeiros são barreiras para a viabilidade das ações e dificultam a atuação dos gestores. São necessários avanços na ESF com mudanças na estrutura organizacional, de gestão e do financiamento do serviço público ${ }^{26}$. Nesse sentido, é imprescindível o apoio financeiro e tecnológico da gestão federal e estadual baseado no princípio da equidade ${ }^{39}$. Este, como entendido por Roncalli ${ }^{40}$, um princípio de justiça social, que pressupõe a organização da assistência, tratando desigualmente os desiguais, e que busca assegurar que os serviços em saúde sejam disponibilizados com base nas diferenças entre os grupos.

Mattos et al. ${ }^{7}$ afirmaram, ainda, que para os gestores a questão financeira tem grande influência na instalação e no desenvolvimento da ESB. Os custos com recursos tecnológicos na prática odontológica, ainda que na atenção primária, são altos. Nesse sentido, alguns participantes da pesquisa caracterizaram a saúde bucal como "cara" devido à grande dependência de tecnologia dura e gastos com pessoal, sendo necessário um melhor investimento na saúde bucal, como forma de melhorar a atenção e aumentar a cobertura.

“[...] A saúde bucal como um todo, e na saúde pública, ela é ainda muito incipiente né? A gente depende de tecnologia dura para a odontologia. Não é igual você ter uma consulta médica que você com o diálogo muitas vezes você resolve o problema. A odontologia ela precisa de um equipamento duro né? A tecnologia dura... é que elas são caras. É cara, a mão de obra é cara pra saúde pública [...]" (E3.GrupolV).

Avanços na qualidade da assistência e maior satisfação dos profissionais com as condições de trabalho, valorização da saúde bucal pelos usuários e pelos próprios profissionais podem ser conquistados com a compra ou troca de muitos materiais odontológicos. Um dos entrevistados acredita existir negligência com equipamentos e/ ou materiais de consumo, causando problemas desnecessários.

"A gestão ela, ela, ela tem que melhorar nessa questão de investimento, de dá uma qualidade melhor sim. A gente precisa rever esses equipamentos, porque assim a gente cai no descrédito né, o profissional, o paciente vai lá tenta agendar a consulta e tá todo dia quebrado a autoclave, tá todo dia quebrado o compressor, isso cai no descrédito, claro, você começa a desanimar entendeu? [...]" (E3. GrupoIV). 
Apesar de a portaria $n^{\circ} 673 / G M$, de 8 de junho de 2003, sugerir a relação de uma ESB para uma EqSF, o município não consegue garantir essa estrutura organizacional no serviço, pois pela Lei de Responsabilidade Fiscal o índice de pessoal seria ultrapassado. Isto se reflete na dificuldade de acesso do usuário ao serviço e compromete a qualidade da atenção ofertada pela equipe, mantendo a alta demanda.

“[...] O que dá uma angustia muito grande pra gente é essa questão do engessar, você ver os problemas de saúde e não poder avançar, né? [...] A gente sabe quais seriam as prováveis soluções, né? E você tem uma meta a ser traçada e você tem impedimentos legais que travam. [...], mas como a gente falou se tiver uma portaria nova que diz que são dois mil pessoas por PSF, e eu não ter... disponibilidade, elasticidade legal pra poder ampliar esse serviço [...]" (E1.GrupolV).

Essa realidade nos leva a refletir sobre a grave consequência da contradição na operacionalização e no financiamento do sistema público de saúde, porque, ao mesmo tempo que exige a ampliação e universalidade da atenção à saúde, limita os gastos com os serviços numa rede de processos burocráticos cheios de antagonismos, tornando-se, na visão de muitos entrevistados. "algo complexo".

"O sistema é muito mais complexo, a gente depende muito mais de órgãos, [...] mais dependentes, por exemplo, eu dependo da secretaria de saúde, a secretaria depende do setor financeiro, que depende do repasse do Estado, do repasse federal [...]. A gestão está sujeita a outras variáveis. Então, o sistema é muito mais complexo." (E5.Grupol).

Entendemos que o baixo financiamento na saúde é uma contradição para um sistema público de caráter universal, pois não permite a resolubilidade dos problemas e a ampliação dos serviços, gera exclusão de muitos usuários que necessitam da saúde pública e contribui para precarização da atenção e das condições de trabalho dos profissionais.

\section{CONCLUSÃO}

Diante da análise realizada, podemos considerar que o município estudado se encontra em fase de aprimoramento do serviço público de saúde. A presença de problemáticas relacionadas à cobertura insuficiente da assistência em saúde bucal tem como consequência uma alta demanda, que produz uma concentração das práticas clínicas de caráter individual em detrimento das ações coletivas voltadas para a promoção e prevenção da saúde, as quais não são valorizadas adequadamente pela população devido à falta de conscientização sobre a sua importância.

Ao mesmo tempo, a forma de organização do serviço, que restringe a marcação de consultas a apenas um indivíduo da família por mês sem a garantia do retorno e baixa oferta de atendimento especializado, prejudica a resolubilidade das ações no momento em que não consegue suprir as demandas no âmbito da atenção básica e no Centro de Especialidades Odontológicas. 
Ademais, podemos considerar como outro entrave para as práticas de saúde bucal o baixo financiamento na saúde. Essa realidade promove a precarização do vínculo empregatício do $C D$ com o município e se reflete na baixa remuneração salarial, levando-o a atuar em outros campos de trabalho, em especial, na clínica privada, e a enfraquecer o vínculo com sua própria equipe e com a comunidade. A não ampliação dos serviços e os problemas com os equipamentos e/ou a falta destes também são reflexos do baixo financiamento e da dificuldade da gestão. Porém, não podemos colocar o financiamento inadequado como um entrave maior do que outros dentro do sistema público de saúde.

Percebemos ainda que, muitas vezes, o profissional é culpabilizado pela não eficiência do serviço. Porém, não podemos simplesmente responsabilizar o profissional sem analisar as condições nas quais o mesmo está inserido, buscando visualizar outros fatores que influenciam diretamente no serviço, como os baixos investimentos por parte do governo, má gestão dos recursos financeiros repassados, formação profissional inadequada, ausência de educação permanente, pouca participação popular, precárias condições de trabalho e de remuneração, além da instabilidade do vínculo empregatício.

Contudo, ressaltamos que mesmo com os entraves identificados, existem Equipes de Saúde Bucal e de Saúde da Família que buscam trabalhar em equipe com foco na integralidade e que, além do atendimento clínico, realizam atividades de cunho educativo, contribuindo para a corresponsabilização e autonomia dos usuários com a saúde. Esses exemplos precisam ser evidenciados para que possam influenciar na disseminação de práticas voltadas para a produção do cuidado.

Diante disso, é preciso salientar que as condições adversas influenciam no bom funcionamento do serviço, mas que o compromisso do profissional com seu trabalho pode ultrapassar alguns limites colocados na prática diária. A vontade de mudar faz com que o profissional busque um olhar ampliado sobre os problemas que o cerca e suas necessidades, leve-o a estudar sobre o meio que está inserido e buscar formas de intervir para avançar, e não apenas ser mais um a reproduzir os entraves com reclamos, sem apresentar medidas que possam trazer soluções.

Isso não quer dizer que o CD deva trabalhar em condições adversas aos princípios da profissão, mas que faça jus à sua escolha de atuar no serviço público e que amplie seu olhar para além da clínica, comprometendo-se com o meio em que está inserido. Assim, é necessária maior responsabilidade de todos os sujeitos envolvidos no cuidar em saúde para garantir a oferta de um serviço de qualidade no qual a resolubilidade seja priorizada e não a continuidade da doença.

Entretanto, pensar dessa forma é também vislumbrar a importância de uma política de saúde do município em que a gestão se empenhe na organização da produção do cuidado dentro das unidades de saúde para que a prática exercida não continue sendo profissional-centrada como acontece no município estudado. 
Além disso, quando analisamos as políticas públicas em saúde com todos os princípios e diretrizes voltados para o sucesso do serviço, indagamos o porquê de a realidade ser tão é diferente do que se propõe nas políticas. Isso nos leva a pensar sobre quem são os idealizadores desse Sistema Único de Saúde e quais são os setores que fornecem os subsídios para o seu funcionamento.

Precisamos refletir sobre o que nos é colocado, aonde queremos chegar e o que estamos fazendo para chegar lá; refletir sobre o tipo de sistema de saúde pública que queremos - aquele sucateado, "de pobre para pobre", ou um serviço de qualidade ao qual todos, independentemente da classe social, tenham acesso. Reproduzir não é nossa tarefa, pois somos seres pensantes. Mas refletir é algo que nos exige muito em um contexto desfavorável, em que a participação social não é estimulada e o controle social foi incorporado pelas instituições e tem colaborado para manipular os interesses sociais.

\section{REFERÊNCIAS}

1. Costa RM, Medeiros Júnior A, Costa ICC, Pinheiro IVA. Processo de trabalho do dentista na estratégia de saúde da família do município de Parnamirim-RN: enfrentando os desafios de um novo modelo de atenção. Rev Odontol Bras Central. 2010; 19(51):327-332.

2. Ministério da Saúde (Brasil). Portaria no 1.444/GM, de 28 de dezembro de 2000. Diário Oficial da União, Brasília, DF, 2000 dez 29.

3. Ministério da Saúde (Brasil). Portaria no 267/GM, de 6 de março de 2001. Diário Oficial da União, Brasília, DF, 2001 mar 7.

4. Barbosa AAA, Brito EWG, Costa ICC. Saúde bucal no PSF, da inclusão ao momento atual: percepções de cirurgiões-dentistas e auxiliares no contexto de um município. Cienc Odontol Bras. 2007 jul-set; 10(3):53-60.

5. Pezzato LM, L'Abbate S, Botazzo C. Produção de micropolíticas no processo de trabalho em saúde bucal: uma abordagem socioanalítica. Ciênc. saúde coletiva [Internet]. 2013 July [citado 2019 maio 24] ; 18(7):2095-2104. Acesso em: http://www.scielo.br/scielo.php?script=sci_arttext\&pid=S141381232013000700025\&lng=en. http://dx.doi.org/10.1590/S141381232013000700025 .

6. Pucca Júnior GA. The national politics of buccal health as social demand. Cien Saude Colet 2006; 11(1):243-246.

7. Mattos GCM, Ferreira e Ferreira E, Leite ICG, Greco RM. A inclusão da equipe de saúde bucal na Estratégia Saúde da Família: entraves, avanços e desafios. Ciência \& Saúde Coletiva. 2014; 19(2):373-382. 
8. Tavares RP, Costa GC, Falcão MLM, Cristino PS. A organização do acesso aos serviços de saúde bucal na estratégia de saúde da família de um município da Bahia. Saúde em Debate. 2013 out/dez; 37(99):628-35.

9. Rodrigues AAAO, Assis MMA. Oferta e demanda na atenção à saúde bucal: o processo de trabalho no programa de saúde da família em Alagoinhas-Bahia. Rev. baiana saúde pública. 2005 jul-dez; 29(2):273-285.

10. Merhy EE. Saúde: a cartografia do trabalho vivo. São Paulo: HUCITEC; 2002. 189 p.

11. Santos AM, Assis MMA, Rodrigues AAAO, Nascimento MAA, Jorge MSB. Linhas de tensões no processo de acolhimento das equipes de saúde bucal do Programa Saúde da Família: o caso de Alagoinhas, Bahia, Brasil. Cad. Saúde Pública. 2007 jan; 23(1):75-85.

12. Rodrigues AAAO, Fonsêca GS, Siqueira DVS, Assis MMA, Nascimento MAA. Práticas da equipe de saúde bucal na estratégia saúde da família e a construção (des) construção da integralidade em Feira de Santana-BA. Rev. APS. 2010 out-dez; 13(4):476-85.

13. Bomfim LS, Pimenta RMC, Rodrigues AAAO. Saúde bucal no Programa Saúde da Família na Bahia. Rev. Saúde. Com. 2013; 9(1):2-15.

14. Pimentel FC, Albuquerque PC, Martelli PJL, Souza WV, Acioli RML. Caracterização do processo de trabalho das equipes de saúde bucal em municípios de Pernambuco, Brasil, segundo porte populacional: da articulação comunitária à organização do atendimento clínico. Cad. Saúde Pública [Internet]. 2012 [citado 2019 maio 24]; 28( Suppl ):s146-s157. Acesso em: http://www.scielo.br/scielo.php?script=sci arttext\&pid=S0102-311X2012001300015\&Ing=en. http://dx.doi.org/10.1590/ S0102-311X2012001300015.

15. Conill EM. Políticas de atenção primária e reformas sanitárias: discutindo a avaliação a partir da análise do Programa Saúde da Família em Florianópolis, Santa Catarina, Brasil, 1994-2000. Cad. Saúde Pública. 2002; 18(Suplemento):191-202.

16. Santos AM, Assis MMA, Nascimento MAA, Jorge MSB. Vínculo e autonomia na prática de saúde bucal no programa de saúde da família. Rev Saúde Pública. 2008; 2(3):464:70.

17. Pereira DQ, Pereira JCM, Assis MMA. A prática odontológica em unidades básicas de saúde em Feira de Santana (BA) no processo de municipalização da saúde individual, curativa, autônoma e tecnicista. Ciência \& Saúde Coletiva. 2003; 8(2):599-609.

18. Mascarenhas LM, Campelo MLL, Carneiro J, Mota C, Gordiano M, Calado MA, et al. Plano municipal de saúde de Conceição do Coité 2014 a 2017. Conceição do Coité; abril, 2014.

19. Fontanella BJB, Ricas J, Turato ER. Amostragem por saturação em pesquisas qualitativas em saúde: contribuições teóricas. Cad. Saúde Pública. 2008;17-27. 
20. Minayo MCS. O desafio do conhecimento: pesquisa qualitativa em saúde. $12^{a}$ ed. São Paulo: HUCITEC; 2010.

21. Relatório anual da gestão 2014. Conceição do Coité; 2015. Disponível em: http://aplicacao.saude.gov.br/sargsus/login!consultarRelatorioExterno. action?tipoRelatorio $=01 \& \operatorname{codUf}=29 \& \operatorname{codTpRel}=01$

22. Ribeiro-Sobrinho C, De Souza LEPF, Chaves SCL. Avaliação da cobertura do Serviço Odontológico da Polícia Militar da Bahia em Salvador, Bahia, Brasil. Cad. Saúde Pública. 2008 fev; 24(2):295-302.

23. Ministério da Saúde (Brasil). Portaria no 599/GM, de 23 de março de 2006. Diário Oficial da União, Brasília, DF, 2006 mar 23.

24. Rodrigues AAAO, Bomfim LS. Saúde bucal no Programa Saúde da Família em município do semiárido baiano (Feira de Santana): organização e micropolítica. Rev. APS. 2010; 13(1):96-108.

25. Ministério da saúde (Brasil). Caderno de Atenção Básica, no 17. Brasília: Ministério da saúde; 2008.

26. Costa RM, Medeiros Júnior A, Costa ICC, Pinheiro IVA. O trabalho em equipe desenvolvido pelo cirurgião-dentista na Estratégia Saúde da Família: expectativas, desafios e precariedades. Rev bras med fam comunidade. 2012 jul-set; 7(24)147-63.

27. Andrade KLC, Ferreira e Ferreira E. Avaliação da inserção da odontologia no Programa Saúde da Família de Pompéu (MG): a satisfação do usuário. Ciência \& Saúde Coletiva. 2006; 11(1):123-30.

28. Pimentel FC, Martelli PJL, Araújo Junior JLAC, Acioli RML, Macedo CLSV. Análise da atenção à saúde bucal na Estratégia de Saúde da Família do Distrito Sanitário VIU, Recife (PE). Ciência \& Saúde Coletiva. 2010; 15(4):2189-96.

29. Barros GB, Cruz JPP, dos Santos AM, Rodrigues AAAO, Bastos KF. Saúde bucal a usuários com necessidades especiais: visita domiciliar como estratégia no cuidado à saúde. Rev. Saúde. Com. 2006; 2(2):135-142.

30. Andrade JWR. Adequação do trabalho do cirurgião-dentista frente às diretrizes da Estratégia de Saúde da Família [trabalho de conclusão de curso]. Teófilo Otoni (MG): Universidade Federal de Minas Gerais, Curso de Especialização em Atenção Básica em Saúde da Família; 2010.

31. Faccin D, Sebold R, Carcereri DL. Processo de trabalho em saúde bucal: em busca de diferentes olhares para compreender e transformar a realidade. Ciência \& Saúde Coletiva. 2010; 15(Supl. 1):1643-52.

32. Rodrigues AAAO. Construção de sujeitos, saberes e práticas na saúde bucal de Alagoinhas - Bahia: o trabalho cotidiano no Programa de Saúde da Família como protagonista da mudança [Dissertação]. Feira de Santana (BA): Universidade Estadual de Feira de Santana; 2005. 
33. Gonçalves ER, Ramos FRS. O trabalho do cirurgião dentista na estratégia de saúde da família: potenciais e limites na luta por um novo modelo de assistência. Interface. 2010 jun; 14(33):301-14.

34. Chaves MC, Miranda AS de. Discursos de cirurgiões-dentistas do Programa Saúde da Família: crise e mudança de habitus na Saúde Pública. Interface. 2008 mar; 12(24):153-67.

35. Chaves SCL, Silva LMV. As práticas profissionais no campo público de atenção à saúde bucal: o caso de dois municípios da Bahia. Ciência \& Saúde Coletiva. 2007; 12(6):1697-1710.

36. Ministério da Saúde (Brasil). Gestão financeira do Sistema Único de Saúde: manual básico. Brasília: Ministério da Saúde, Fundo Nacional de Saúde; 2003. 66 p.

37. Moimaz SAS, Garbin CAS, Garbin AJI, Ferreira NF, Gonçalves PE. Desafios e dificuldades do financiamento em saúde bucal: uma análise qualitativa. Rev Adm Pública. 2008 dez; 42(6):1121-35.

38. Antunes JLF, Narvai PC. Políticas de saúde bucal no Brasil e seu impacto sobre as desigualdades em saúde. Rev. Saúde Pública. 2010 abr; 44(2):360-5.

39. Copque HLF, Trad LAB. Programa Saúde da Família: a experiência de implantação em dois Municípios da Bahia. Epidemiologia e Serviços de Saúde. 2005 out-dez; 14(4):223-33.

40. Roncalli AOG. A organização da demanda em serviços públicos de saúde bucal: universalidade, equidade e integralidade em saúde pública coletiva [Tese]. Araçatuba (SP): Universidade Estadual Paulista Júlio de Mesquita Filho; 2000.

Submissão: junho de 2016

Aprovação: setembro de 2019. 